\title{
Culture and work: Relationship between socio-cultural values and organizational commitment among bank managers in Ghana using SEM/PLS approach
}

Opoku Mensah, Abigail $\$

University of Cape Coast, Ghana (aopokumensah@ucc.edu.gh)

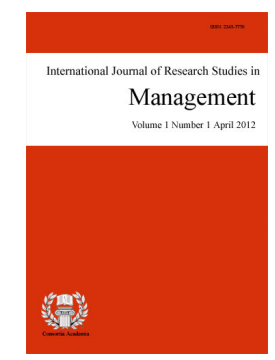

ISSN: $2243-7770$ Online ISSN: 2243-7789

Received: 3 October 2017

Revised: 9 October 2017 DOI: $10.5861 /$ ijrsm.2018.2002

Accepted: 16 November 2017

\section{Abstract}

The study investigated the relationship between socio-cultural values and organizational commitment using a sample of 211 bank managers from three regions in Ghana. The study design was cross-sectional survey using questionnaire as the main instrument for data collection on: socio-cultural values and organizational commitment. The study was underpinned by the socio-cultural sub-system model. Data was analyzed using structural equation modeling (partial least square).The results of the study confirm the authors' hypotheses: Employees adherence to Socio-cultural values had a positive effect on organizational commitment. The findings of the study therefore suggest that employers and management should pay attention to employees' socio-cultural values and consider integrating these individuals' socio-cultural values into the organizational culture in order to promote employees commitment to work. It does also provide information for theory building and policy formulation as elaborated in the main study.

Keywords: socio-cultural values; organizational commitment; workplace; Ghana 


\section{Culture and work: Relationship between socio-cultural values and organizational commitment among bank managers in Ghana using SEM/PLS approach}

\section{Introduction}

Every society has its own unique cultural values which guide the way the people live and take decision which affect the quality of work and other relationships. According to Hofstede (1980) and Pasa, Kabasakal, and Bobur (2001), socio-cultural values are values, attitudes and beliefs that are shared among a group of people in a society which make them distinct as a collective group from others. These values as indicated by Mugunthan (2013), Gyekye (2003), and Gbadamosi (2003) influence individuals' attitudes and behavior wherever they find themselves including the workplace. This clearly suggests a possible link between employees' socio-cultural values and organizational commitment at the workplace.

Consequently, it is argued that socio-cultural values which continue to remain strong among individuals at the workplace in spite of all its conflicting values with organizational culture could influence work attitude specifically their organizational commitment. For instance, Akuoko (2008) indicated that despite the rapid changes the Ghanaian society has undergone, it still retains most of the norms of its traditional society for most of its people living in the traditional society.

There are some empirical studies that assess culture and employees' work attitudes; however, the attention has been on only one specific socio-cultural value (religiosity). Most of these studies were also done in countries such as USA and Western European countries. According to Ali, Akuahmoah-Boateng, Bowa, et al. (2001), the African culture has its own unique features which need to be investigated to find its influence on employees work attitudes in order to improve the management of organizations to make it more effective. In response to this, undertaking a holistic study to find out the kind of relationships that may exist between socio-cultural values holistically and employees organizational commitment have been explored in this study to expand our understanding of this relationship from an African perspective.

\subsection{Socio-cultural subsystem}

This subsystem takes into account an integral part of the social system theory which brings about the kind of relationship that exists between an organization's culture and that of the individual ambient society in which they live and work. According to Nukunya (2013), culture influences productivity, work ethics and other aspects of the economy. This however, according to Apekey (2001), explains the bases for an individual's behavior and attitude at work. Employees, to a large extent may maintain their cultural values even when they work in an organization that does not take into account their cultural values. Their indigenous values will still influence them. Apekey (2001) argued that Ghanaians' cultural values have remained relevant in predicting and influencing the people's attitudes and behavior. Some empirical works by Saari and Erez (2002) and Saari and Judge (2004) have confirmed that employees' work attitudes are influenced by culture.

From the above analysis, individuals will unconsciously transfer the societal cultural values to the workplace which may have influence on their work attitude (organizational commitment). Based on the socio-cultural subsystem view, the study dwells on the assumption that though every work settings has its own organizational culture, its members' behaviors and attitudes toward work would be influenced by their societal-cultural values as well.

\section{Literature review}

Attitude toward authority is exhibited by showing "respect" which is considered as one of the cardinal 
socio-cultural values among the people of Ghana (Gyekye, 2003). The Ghanaian culture frowns upon individuals who disrespect fellow human beings especially the aged even when they are wrong and you are right. The issue of respect at the workplace has become a critical issue to both employees and employers. Mayhew (2015) indicated that respect for co-workers inspires collegial work environment which have influence on their work attitudes such as organizational commitment and job satisfaction. Respecting each other at the workplace according to him fosters collaboration, synergy and cooperation which are considered as essential features for creating workforce that values productivity. Where there is no respect among employees or from subordinate to those in authority at the workplace the incidence of low commitment level is likely to arise.

Africans, specifically, Ghanaians are deemed very religious which is also considered as one of the important socio cultural values (Gyekye, 2003). Though some researchers suggested that religious values ${ }^{1}$ have little or no bearing on the way people view work hence have no link with work attitudes (Mortimer \& Lorence, 1995; Lincoln \& Kalleberg, 1985), others suggest that religiosity can influence organizational commitment, job satisfaction and Organizational Citizenship.

According to Abdul, Jusoh, Amlus, and Halim (2013), a person's 'religious values' have a positive influence on work attitudes (organizational commitment). A recent study by Roger and Franzen (2014) also revealed similar results which indicated that 'religion' have an effect on individual behavior. Other findings showed that religious beliefs influence several aspects of a person's life, increase self-esteem and commitment (Ebrahimi \& Nasir, 1996). This according to Gelder (2012) also influence the way individuals behave at the workplace. Other empirical works by Saari and Erez (2002) have also shown that employees' work attitudes are influenced by culture whereas Abbott, White, and Charles (2005) found that common values affect organizational commitment of employees at the workplace.

On the contrary, according to Tahmincioglu (2012), though, employees have religious rights in the workplaces, wearing their religion on their sleeve at work can be hazardous to their career. Prenkert (2012) argued that despite the fact that there are religious rights for employees who are covered under Title VII of the Civil Rights Act of 1964; religious conflict is becoming common in this modern world, compared to some few decades ago when the workplace was more homogenous. The controversy in the literature makes the focus of the study also very much relevant.

\subsection{Conceptual framework}

(Organizational Commitment-OC)

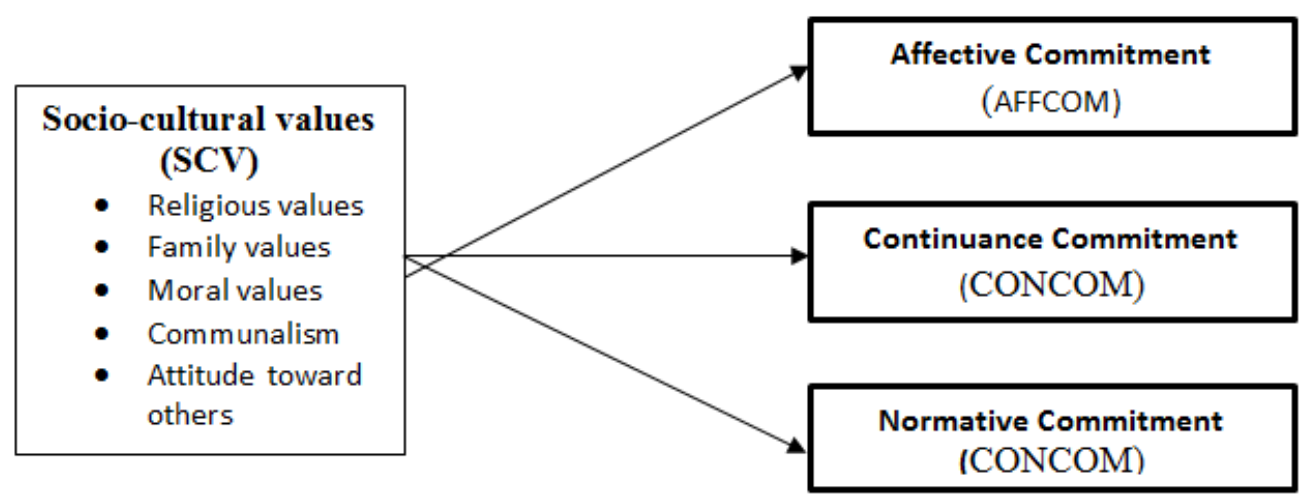

Figure 1. Hypothesized relationships between endogenous variable and exogenous variable as conceptualized in this study

1 Religious value: this value explains the believe in a supreme being which makes an individual lead a righteous life which is pleasing onto God such as being humble, respectful, speaking the truth, not hurting your neighbor, being kind and compassionate. 
$>\quad H_{1}$ : Socio-cultural values (SCV) will have a significant positive effect on organizational commitment.

$>\quad H_{2}$ : Socio-cultural values $(\mathrm{SCV})$ will have a significant positive effect on affective commitment ${ }^{2}$.

$>\quad H_{3}$ : Socio-cultural values $(\mathrm{SCV})$ will have a significant positive effect on continuance commitment ${ }^{3}$.

$>\quad \boldsymbol{H}_{4}$ : Socio-cultural values (SCV) will have a significant positive effect on normative commitment ${ }^{4}$.

$>\quad H_{5}: \operatorname{SCVC}$ (Communal values) will have a significant positive effect on affective, continuance and normative commitment.

$>\boldsymbol{H}_{\boldsymbol{6}}$ : Socio-cultural values (Attitude toward others ${ }^{5}$ ) will have a significant positive effect on affective, continuance and normative commitment.

$>\quad \boldsymbol{H}_{7}$ : Socio-cultural values (Family values ${ }^{6}$ ) will have a significant positive effect on affective, continuance and normative commitment.

$>\quad \boldsymbol{H}_{\boldsymbol{g}}$ : Socio-cultural values (Religious values) will have a significant positive effect on affective, continuance and normative commitment.

$>\quad \boldsymbol{H}_{9}$ : Socio-cultural values (Moral values ${ }^{7}$ ) will have a significant positive effect on affective, continuance and normative commitment.

\section{Methodology}

Study Area - Bank managers in financial services sector from three regions (Greater Accra, Ashanti and Western Region) in Ghana.

Population and Sample - The population for the study was Bank Managers ${ }^{8}$ in licensed commercial bank in Ghana. Participants were selected using purposive sampling technique which allowed the researcher to select only Bank Managers for the study.

Instruments - Organizational commitment was assessed with the revised 19-item Organizational Commitment questionnaire by Allen and Meyer (2000). The responses were arrayed on a five-point Likert scale which ranged from (1) strongly disagree to (5) strongly agree. Cronbach's alpha was 0.82. After the final measurement model analysis, affective commitment scale reported a Cronbach alpha coefficient of 0.99 with 4 items that loaded well. Continuance commitment also reported Cronbach alpha coefficient of 0.99 with 5 items that loaded well. Lastly, normative commitment had a Cronbach alpha coefficient of 0.98 with 4 retained items. The minimum score on the scale was 19 and the maximum 95.

Socio-cultural value scale developed by Opoku Mensah (n.d) was used in measuring socio-cultural values at work $^{9}$. The scale consists of eighteen-items with five index variables: Moral values (3 items), religious values (3

\footnotetext{
2 Affective commitment refers to an employee's attachment with his or her working institution and the organizational goals.

${ }^{3}$ Continuance commitment refers to an employee's organizational commitment because of the kind of work-relationships that exist and other benefits, or the material benefits gained from being with the organization

${ }^{4}$ Normative commitment has to do with the sense of obligation of an employee, based on his values and norms

5 Attitude toward others: this describes 'good character' (Gyekye, 2003). It describes the kind attitude and behavior that is acceptable in a particular society.

${ }^{6}$ Family values: having the belief that whatever behavior one exhibit outside the home is more often than associated with the family we belong. This value makes one conscious of whatever behavior/ action they exhibit.

7 Moral values are described to be intrinsic and it is mostly anchored in people's beliefs about what is right and wrong.

${ }^{8}$ For the purpose of this study Bank Managers formed the sample. It is argued in the literature that employees who occupy managerial positions are expected to perform multiple tasks and also have to show examples of positive work attitudes for subordinates to follow.

9 They are societal values which individuals transfer to the workplace which has the possibility of influencing their attitudes and behavior.
} 
items), communalism ${ }^{10}$ (5 items), Attitude toward others (4 items) and family values (3 items). Five-point response Likert scale ranged from (1) strongly disagree to (5) strongly agree) was used. The scale reported a Cronbach alpha of 0.72 suggesting that the items on the scale have relatively high internal consistency. After the final measurement model analysis, Moral values reported a Cronbach alpha of 0.35 after deletion of an item which did not load well. Attitude toward others (Cronbach alpha of 0.98) with 3 retained items, Religious and family values reported 0.96 and 0.97 respectively with 3 items each which loaded well. Communalism reported Cronbach alpha of 0.97 with 5 items which also loaded well. The minimum score on the scale was 18 and the maximum 90.

Data analysis - Partial Least Squares (PLS) structural equation modelling technique ${ }^{11}$ was adopted to measure the interrelationships. Organizational Commitment as a construct was measured as a second-order or higher-order formative construct using the reflective-reflective type of hierarchical component modelling (Ringle, Sarstedt, \& Straub, 2012). Such higher-order models allow for the forming of a new (higher-order) variable as a composite of several other constructs (lower-level). This is advantageous since it reduces the number of relationships to be tested in the structural model thereby ensuring more parsimonious model as well as dealing with issues of highly correlated sub-variables which may result in collinearity and discriminant validity issues (Hair, Hult, Ringle, \& Sarstedt, 2014). Therefore, Organizational Commitment is the higher-order construct which comprises Affective Commitment (AFFCOM), Normative Commitment (NORMCOM) and Continuous Commitment (CONCOM). The reflective-reflective model for measuring the second-order formative construct follows the same reflective procedure in assessing the measurement model, therefore initial and final results of each of the lower-order construct are presented in the tables below. Socio-Cultural Values are first modelled as a second-order formative construct similar to Organizational Commitment. This is because the construct has 5 separate dimensions which must all be available to measure the socio-cultural values of respondents. Note that whereas socio-cultural value is the higher order construct, the lower order constructs include: attitudes towards others (SCVATO), communalism (SCVC), family values (SCVF), moral values (SCVMV) and religious values (SCVR).

\section{Results}

\subsection{Measurement model}

Table 1 shows the final measurement model after deleting items that did not load well which improved the validity and reliability of the indicators. The AVE now stands at $97.82 \%$ signifying a high communality over and above the minimum threshold of $50 \%$. Similarly, the reliability of the construct is between $99.26 \%$ and $99.45 \%$ as indicated by the Cronbach's alpha and Composite Reliability respectively; finally, all loadings are above 0.9 which provides a sufficient assurance of discriminant validity at the indicator level.

\section{Table 1}

Affective Commitment - Final Measurement Model

\begin{tabular}{|c|c|c|c|c|}
\hline Items & & Loadings & Mean & $S D$ \\
\hline I am very happy being a member of this organization. & COMAFF1 & 0.989 & 4.4123 & 0.5216 \\
\hline $\begin{array}{l}\text { I enjoy discussing about my organization with people } \\
\text { outside it. }\end{array}$ & COMAFF2 & 0.9842 & 4.4123 & 0.5216 \\
\hline I really feel as if this organization's problems are my own. & COMAFF3 & 0.9893 & 4.4171 & 0.5224 \\
\hline $\begin{array}{l}\text { I think that I could easily become as attached to another } \\
\text { organization as I am to this one.(R) }\end{array}$ & COMAFF4 & 0.9936 & 4.4076 & 0.5207 \\
\hline
\end{tabular}

Note. AVE: 0.98; Composite Reliability: 0.99; Cronbach Alpha: 0.99

\footnotetext{
${ }^{10}$ Communalism: This societal value refers to this value underpins and guides the type of social relations, attitude and behavior that ought to exist between individuals who live together in a community. This is demonstrated by showing love and seeing to the well-being of other people in the community.

11 This technique forms the regression aspect of the analysis which helps to establish the kind of relationship that exists between exogenous variable and endogenous variable.
} 
Not surprisingly, the validity and reliability measures improve when an item 'COMCONT8' was deleted. AVE improved to 0.9599 from an initial 0.8067 while Composite Reliability and Cronbach alpha changed from 0.9758 and 0.9311 to 0.9917 and 0.9895 respectively. All loadings were above 0.9 providing a good basis for discriminant validity. Also, the Means and Standard deviations for all manifest variables are quite similar, which shows good homogeneity in the variance of the individual manifest variables.

\section{Table 2}

Continuous Commitment- Final Measurement Model

\begin{tabular}{|c|c|c|c|c|}
\hline Items & & Loadings & Mean & $S D$ \\
\hline $\begin{array}{l}\text { If I wasn't a member of this organization, I would be } \\
\text { sad because my life would be disrupted. }\end{array}$ & COMCONT9 & 0.9874 & 4.3175 & 0.4666 \\
\hline $\begin{array}{l}\text { I am loyal to this organization because I have } \\
\text { invested a lot in it, emotionally, socially, and } \\
\text { economically. }\end{array}$ & COMCONT10 & 0.9828 & 4.3081 & 0.4628 \\
\hline $\begin{array}{l}\text { I often feel anxious about what I have to lose with } \\
\text { this organization }\end{array}$ & COMCONT11 & 0.9745 & 4.3270 & 0.4702 \\
\hline $\begin{array}{l}\text { Sometimes I worry about what might happen if } \\
\text { something was to happen to this organization and I } \\
\text { was no longer a member. }\end{array}$ & COMCONT12 & 0.9758 & 4.3128 & 0.4647 \\
\hline $\begin{array}{l}\text { I am dedicated to this organization because I fear } \\
\text { what I have to lose in it. }\end{array}$ & COMCONT13 & 0.9781 & 4.3081 & 0.4628 \\
\hline
\end{tabular}

Just like Affective Commitment and Continuous Commitment, the reliability and convergent validity measures for the latent variable are all above the thresholds for Normative Commitment. This is probable because these Commitment variables have had sufficient theoretical and empirical testing in previous research and have been adequately validated. However, there were concerns of discriminant validity since some manifest variables had very low loadings. Loadings of 0.3349 and 0.1987 are very low and warrant that the manifest variables corresponding to these loadings be deleted. Therefore, two items 'COMNORM18' and 'COMNORM19' were deleted to ensure parsimony in the measurement model. The loadings of the manifest variables therefore ranged from 0.9728 to 0.9780 which are adequately high.

Table 3

Normative Commitment- Final Measurement Model

\begin{tabular}{|c|c|c|c|c|}
\hline Items & & Loadings & Mean & $S D$ \\
\hline $\begin{array}{l}\text { I feel that I owe this organization quite a bit } \\
\text { because of what it has done for me. }\end{array}$ & COMNORM14 & 0.9780 & 4.3602 & 0.4812 \\
\hline $\begin{array}{l}\text { My organization deserves my loyalty because of } \\
\text { its treatment towards me. }\end{array}$ & COMNORM15 & 0.9679 & 4.3649 & 0.4826 \\
\hline $\begin{array}{l}\text { I feel I would be letting my co-workers down if I } \\
\text { was not a member of this organization. }\end{array}$ & COMNORM16 & 0.9728 & 4.3460 & 0.4768 \\
\hline $\begin{array}{l}\text { I am loyal to this organization because my values } \\
\text { are largely its values }\end{array}$ & COMNORM17 & 0.9610 & 4.3507 & 0.4783 \\
\hline
\end{tabular}

Final measurement model for moral values for example sees large improvements in the AVE and the Composite reliability measures. AVE is now 0.6062 which is above the 0.5 threshold. Composite reliability is now also above the 0.7 band. Cronbach's alpha however remains below the minimum acceptable value of 0.7 . The construct recorded an alpha score of 0.3529. While this looks unacceptable, in PLS-SEM modelling, more reliance is placed on the results of the Composite reliability than the Cronbach's alpha (Hair et al., 2014; Henseler, Christian Ringle, \& Sinkovics, 2009). This is because the Cronbach's alpha provides a severe underestimation of the internal consistency reliability of the latent variable in PLS model (Henseleret al., 2009). Therefore since the Composite reliability indicator satisfies the minimum acceptable threshold of 0.7 , internal 
consistency has been achieved. For the second construct, attitude toward others, the problem was with the loadings of the fourth manifest variable 'SCVATO4'. Removing this item improved the AVE from 0.7435 to 0.967 while the reliability indices for Composite reliability and Cronbach's alpha improved from 0.9124 and 0.8495 to 0.9887 and 0.9829 respectively. Factor loadings ranged from 0.9799 to 0.9863 which indicate good discriminant validity at the item level.

\section{Table 4}

Socio-Cultural Values at work- Final Measurement Model

\begin{tabular}{|c|c|c|c|c|c|}
\hline \multirow[t]{4}{*}{1.} & \multicolumn{5}{|l|}{ Moral Values } \\
\hline & AVE: 0.61; CR: 0.75; Cronbach Alpha: 0.35 & & Loadings & Mean & $S D$ \\
\hline & We should always be faithful to one another. & SCVMV1 & 0.7367 & 4.3507 & 0.4783 \\
\hline & $\begin{array}{l}\text { It is important to lead a good life for others to } \\
\text { follow. }\end{array}$ & SCVMV2 & 0.8184 & 4.3839 & 0.5852 \\
\hline \multirow[t]{5}{*}{2.} & \multicolumn{5}{|l|}{ Attitude Toward Others } \\
\hline & AVE: 0.97; CR: 0.99; Cronbach Alpha: 0.98 & & Loadings & Mean & $S D$ \\
\hline & $\begin{array}{l}\text { Employees/subordinates should obey superiors } \\
\text { instructions even when they think they do not } \\
\text { agree with them }\end{array}$ & SCVATO1 & 0.9799 & 4.2891 & 0.5664 \\
\hline & $\begin{array}{l}\text { Employees should follow organizational } \\
\text { policies even when they think the policies are } \\
\text { unfair to them }\end{array}$ & SCVATO2 & 0.9863 & 4.2559 & 0.5528 \\
\hline & $\begin{array}{l}\text { Subordinates should always humble and support } \\
\text { their superior's decisions, even if they do not } \\
\text { agree with him }\end{array}$ & SCVATO3 & 0.9839 & 4.2512 & 0.5507 \\
\hline \multirow[t]{5}{*}{3.} & \multicolumn{5}{|l|}{ Religious Values } \\
\hline & AVE: 0.93; CR: 0.97; Cronbach Alpha: 0.96 & & Loadings & Mean & $S D$ \\
\hline & $\begin{array}{l}\text { My religious beliefs are what really lie behind } \\
\text { my whole approach to work }\end{array}$ & SCVRV1 & 0.9761 & 4.2512 & 0.5507 \\
\hline & $\begin{array}{l}\text { My faith sometimes restricts some of my actions } \\
\text { at work. }\end{array}$ & SCVRV2 & 0.9548 & 4.2417 & 0.5463 \\
\hline & $\begin{array}{l}\text { I believe whatever happens to me in life has } \\
\text { spiritual causes. }\end{array}$ & SCVRV3 & 0.9590 & 4.2749 & 0.5609 \\
\hline \multirow[t]{5}{*}{4.} & \multicolumn{5}{|l|}{ Family Values } \\
\hline & AVE: 0.94; CR: 0.98; Cronbach Alpha: 0.97 & & Loadings & Mean & $S D$ \\
\hline & $\begin{array}{l}\text { My family expectations influence my behaviour } \\
\text { at the workplace }\end{array}$ & SCVF1 & 0.9857 & 4.3033 & 0.4608 \\
\hline & $\begin{array}{l}\text { Meeting my family demands comes first before } \\
\text { my work }\end{array}$ & SCVF2 & 0.9679 & 4.3175 & 0.4666 \\
\hline & $\begin{array}{l}\text { A person should always think about their family } \\
\text { when making important decisions }\end{array}$ & SCVF3 & 0.9574 & 4.3175 & 0.4666 \\
\hline \multirow[t]{7}{*}{5.} & \multicolumn{5}{|l|}{ Communalism } \\
\hline & AVE: 0.90; CR: 0.98; Cronbach Alpha: 0.97 & & Loadings & Mean & $S D$ \\
\hline & $\begin{array}{l}\text { Sharing work ideas at the workplace is } \\
\text { important. }\end{array}$ & SCVC1 & 0.9629 & 4.327 & 0.4702 \\
\hline & $\begin{array}{l}\text { It is always important to be united as members } \\
\text { of an organization }\end{array}$ & $\mathrm{SCVC} 2$ & 0.9765 & 4.327 & 0.4702 \\
\hline & We mourn and laugh together at the workplace & SCVC3 & 0.9296 & 4.3128 & 0.4647 \\
\hline & $\begin{array}{l}\text { I see myself and other employees belonging to } \\
\text { one group }\end{array}$ & SCVC4 & 0.9453 & 4.3128 & 0.4647 \\
\hline & $\begin{array}{l}\text { Experienced employees should mentor } \\
\text { inexperienced employees at the workplace. }\end{array}$ & SCVC5 & 0.9204 & 4.3033 & 0.4608 \\
\hline
\end{tabular}

A minimum loading of 0.6 is required for inclusion in the model. For all first order constructs (sub constructs of OC and SCV), this criteria is achieved. Factor loadings for these sub constructs range from 0.7001 to 0.9936 which indicates good discriminant validity at the item level. From the table, however, the minimum loadings for the two second order constructs (OC and SCV) are lower than the acceptable levels. This is because they are not being directly measured but are a composite of several sub constructs. Therefore, achieving 
Opoku Mensah, A.

discriminant validity at the sub construct level provides reasonable validity at the higher order level. Additionally, $\mathrm{OC}$ and SCV are measure formatively (as second order formative constructs) which does not place much reliance on validity and reliability but rather on theoretical justification (Hair et al., 2009).

Table 5

Summary of the Final Measurement Model for Construct

\begin{tabular}{lccccc}
\hline \multicolumn{1}{c}{ Construct } & \multirow{2}{*}{ AVE } & $\begin{array}{c}\text { Composite } \\
\text { Reliability }\end{array}$ & $\begin{array}{c}\text { Cronbach } \\
\text { Alpha }\end{array}$ & Loadings Range & Items $^{\mathrm{a}}$ \\
\hline Organizational Commitment (OC) & 0.6293 & 0.9501 & 0.9402 & $0.2845-0.9493$ & $\left(19^{a}\right) 13^{*}$ \\
Affective Commitment (AFFCOM) & 0.9782 & 0.9945 & 0.9926 & $0.9842-0.9936$ & $\left(7^{a}\right) 4^{*}$ \\
Continuous Commitment (CONCOM) & 0.9599 & 0.9917 & 0.9895 & $0.9745-0.9874$ & $\left(6^{a}\right) 5^{*}$ \\
Normative Commitment (NORMCOM) & 0.9408 & 0.9845 & 0.9790 & $0.9610-0.9780$ & $\left(6^{a}\right) 4^{*}$ \\
Socio-Cultural Values (SCV) & 0.5275 & 0.9432 & 0.9332 & $0.2300-0.8782$ & $\left(18^{a}\right) 16^{*}$ \\
Attitudes Towards Others (SCVATO) & 0.9670 & 0.9887 & 0.9829 & $0.9801-0.9862$ & $\left(4^{a}\right) 3^{*}$ \\
Communalism (SCVC) & 0.8971 & 0.9776 & 0.9712 & $0.9207-0.9764$ & $\left(5^{a}\right) 5^{*}$ \\
Family Values (SCVF) & 0.9417 & 0.9798 & 0.9690 & $0.9573-0.9857$ & $\left(3^{a}\right) 3^{*}$ \\
Moral Values (SCVMV) & 0.6042 & 0.7516 & 0.3529 & $0.7001-0.8474$ & $\left(3^{a}\right) 2^{*}$ \\
Religious Values (SCVR) & 0.9281 & 0.9748 & 0.9612 & $0.9551-0.9760$ & $\left(3^{a}\right) 3^{*}$ \\
\hline
\end{tabular}

Note. ${ }^{\text {a }}$ (Initial Number of items. *Final items

Values in the diagonal section for most latent variables are largely greater than its correlations with other variables. The main issue is with some of the dimensions of socio-cultural values of respondents. For example, whereas the squared AVE of religious values at work (SCVR) is 0.9634, the correlation between SCVR and SCVATO stands at 0.9715 which is larger than the squared AVE. This raises concerns on the discriminant validity of the model at the construct level. However, it needs to be remembered that socio-cultural value is being measured as a second order construct. Therefore, SCVR, SCVATO, SCVC, SCVF and SCVMV are all lower order constructs of the higher order construct- socio-cultural values. Since one of the main reasons for the use of socio-cultural values as a second-order formative construct is because of the possible collinearity among the sub constructs (Ruiz, Gremler, Washburn, \& Carrion, 2010; Mathwick, Malhotra, \& Rigdon, 2001), this finding provides both the necessary justification for the use of the second-order construct and enough assurance that possible issues with these correlated variables have been duly catered for.

Table 6

Discriminant Validity Test

\begin{tabular}{ll|cc|cccccccc}
\hline & Factors & Mean & SD & 1 & 2 & 3 & 4 & 5 & 6 & 7 & 8 \\
\hline 1 & AFFCOM & 31.04 & 2.57 & $\mathbf{0 . 9 8 9 0}$ & & & & & & \\
2 & CONCOM & 26.03 & 2.42 & 0.1373 & $\mathbf{0 . 9 7 9 7}$ & & & & & \\
3 & NORMCOM & 25.68 & 2.25 & 0.1802 & 0.8646 & $\mathbf{0 . 9 6 9 9}$ & & & & \\
4 & SCVATO & 17.04 & 1.83 & 0.3301 & 0.0785 & 0.1308 & $\mathbf{0 . 9 8 3 4}$ & & & \\
5 & SCVC & 21.58 & 2.21 & 0.1463 & 0.3353 & 0.2969 & 0.2841 & $\mathbf{0 . 9 4 7 2}$ & & \\
6 & SCVF & 12.94 & 1.35 & 0.1165 & 0.2885 & 0.2267 & 0.2773 & 0.9461 & $\mathbf{0 . 9 7 0 4}$ & & \\
7 & SCVMV & 13.04 & 1.02 & 0.5193 & 0.7109 & 0.8270 & 0.2591 & 0.2431 & 0.1643 & $\mathbf{0 . 7 7 7 3}$ & \\
8 & SCVR & 12.77 & 1.60 & 0.3177 & 0.0769 & 0.0987 & 0.9715 & 0.2888 & 0.2867 & 0.2237 & $\mathbf{0 . 9 6 3 4}$ \\
\hline
\end{tabular}

\subsection{Structural Model}

The structural model is the theoretical model (Haenlein \& Kaplan, 2004) which is the regression side of the PLS-SEM assessment. The results of the structural model, after bootstrapping and blindfolding algorithms, have therefore been presented in Tables 7 and 8. Two models are tested in table 7. First model looks at how SCV affects OC at the composite level. The second model then looks at the effect of SCV on the sub components of organizational commitment. From the table, $R^{2}$ values range from $7.83 \%$ to $14.38 \%$. Although high $R^{2}$ values are preferable, in exploratory assessments, low $R^{2}$ values are sometimes expected. All $Q^{2}$ values are positive signifying that the models have reasonable predictive relevance. 
Relationship between socio-cultural values and organizational commitment using SEM/PLS approach

Table 7

Path Coefficients

\begin{tabular}{|c|c|c|c|c|c|c|c|c|c|c|}
\hline \multicolumn{4}{|c|}{ Model } & \multirow{2}{*}{$\begin{array}{c}\text { Coefficient } \\
0.3792\end{array}$} & \multirow{2}{*}{$\begin{array}{c}\text { S.E } \\
0.0696\end{array}$} & \multirow{2}{*}{$\begin{array}{c}\text { t stat } \\
5.4444\end{array}$} & \multicolumn{2}{|l|}{ Sig. } & \multirow{2}{*}{$\begin{array}{c}R^{2} \\
0.1438\end{array}$} & \multirow{2}{*}{$\frac{Q^{2}}{0.142}$} \\
\hline 1. & SCV & $\rightarrow$ & $\mathrm{OC}$ & & & & 0.000 & $* * *$ & & \\
\hline \multirow{3}{*}{2.} & SCV & $\rightarrow$ & AFFCOM & 0.2796 & 0.0676 & 4.1335 & 0.0000 & $* * *$ & 0.0783 & 0.0764 \\
\hline & SCV & $\rightarrow$ & CONCOM & 0.3435 & 0.0745 & 4.612 & 0.0000 & $* * *$ & 0.1181 & 0.1123 \\
\hline & SCV & $\rightarrow$ & NORMCOM & 0.3330 & 0.0716 & 4.6518 & 0.0000 & $* * *$ & 0.1111 & 0.1038 \\
\hline
\end{tabular}

Note. $p<0.05^{*}, p<0.01^{* *}, p<0.001^{* * * *}$

Now to the path coefficients, starting with model 1, the results of the SEM/PLS analysis indicates that socio-cultural values have a significant positive effect on organizational commitment $(\beta=0.3792, p<0.001)$. This means that persons who have higher socio-cultural values have higher levels of commitment towards the organization. This significantly positive effect is seen irrespective of the dimension of commitment under consideration. This is because, from model $2, \mathrm{SCV}$ is seen to have significantly positive effects on affective commitment $(\beta=0.2796, p<0.001)$, continuous commitment $(\beta=0.3435, p<0.001)$ and normative commitment as well $(\beta=0.3330, p<0.001)$. Judging from the coefficients, SCV seems to have greatest impact on continuous commitment and normative commitment compared to its impact on affective commitment.

To provide additional information on the mechanism through which SCV affects organizational commitment, the sub dimensions of SCV are also regressed on OC at the composite level and at sub construct levels in model 3 to model 6. This is presented in Table 8.

Table 8

Path Coefficients

\begin{tabular}{|c|c|c|c|c|c|c|c|c|c|c|}
\hline & Model & & & Coefficient & S.E & t stat & Sig. & & $R^{2}$ & $Q^{2}$ \\
\hline \multirow{5}{*}{3.} & SCVATO & $\rightarrow$ & $\mathrm{OC}$ & -0.2588 & 0.1962 & 1.3189 & 0.1878 & \multirow{5}{*}{$* * *$} & \multirow{5}{*}{0.7335} & \multirow{5}{*}{0.7198} \\
\hline & SCVC & $\rightarrow$ & $\mathrm{OC}$ & 0.0576 & 0.1512 & 0.3812 & 0.7032 & & & \\
\hline & SCVF & $\rightarrow$ & $\mathrm{OC}$ & 0.1161 & 0.1480 & 0.7846 & 0.4331 & & & \\
\hline & SCVMV & $\rightarrow$ & $\mathrm{OC}$ & 0.8378 & 0.0267 & 31.4068 & 0.0000 & & & \\
\hline & SCVR & $\rightarrow$ & $\mathrm{OC}$ & 0.146 & 0.1931 & 0.756 & 0.4500 & & & \\
\hline \multirow{5}{*}{4.} & SCVATO & $\rightarrow$ & AFFCOM & 0.0311 & 0.2389 & 0.1302 & 0.8965 & \multirow{5}{*}{$* * *$} & \multirow{5}{*}{0.2195} & \multirow{5}{*}{0.2053} \\
\hline & SCVC & $\rightarrow$ & AFFCOM & -0.0965 & 0.1910 & 0.5048 & 0.6139 & & & \\
\hline & SCVF & $\rightarrow$ & AFFCOM & 0.0659 & 0.1840 & 0.358 & 0.7205 & & & \\
\hline & SCVMV & $\rightarrow$ & AFFCOM & 0.4817 & 0.0663 & 7.2665 & 0.0000 & & & \\
\hline & SCVR & $\rightarrow$ & AFFCOM & 0.1887 & 0.2455 & 0.7687 & 0.4424 & & & \\
\hline \multirow{5}{*}{5.} & SCVATO & $\rightarrow$ & CONCOM & -0.4705 & 0.3667 & 1.2828 & 0.2002 & \multirow{5}{*}{$* * *$} & \multirow{5}{*}{0.6799} & \multirow{5}{*}{0.6505} \\
\hline & SCVC & $\rightarrow$ & CONCOM & 0.0342 & 0.2377 & 0.1439 & 0.8856 & & & \\
\hline & SCVF & $\rightarrow$ & CONCOM & 0.1783 & 0.2329 & 0.7654 & 0.4444 & & & \\
\hline & SCVMV & $\rightarrow$ & CONCOM & 0.7256 & 0.0446 & 16.2517 & 0.0000 & & & \\
\hline & SCVR & $\rightarrow$ & CONCOM & 0.3107 & 0.3611 & 0.8603 & 0.3900 & & & \\
\hline \multirow{5}{*}{6.} & SCVATO & $\rightarrow$ & NORMCOM & 0.0047 & 0.1471 & 0.0322 & 0.9743 & \multirow{5}{*}{$* * *$} & \multirow{5}{*}{0.8617} & \multirow{5}{*}{0.8039} \\
\hline & SCVC & $\rightarrow$ & NORMCOM & 0.1193 & 0.1147 & 1.0406 & 0.2986 & & & \\
\hline & SCVF & $\rightarrow$ & NORMCOM & 0.0141 & 0.1148 & 0.1225 & 0.9026 & & & \\
\hline & SCVMV & $\rightarrow$ & NORMCOM & 0.8233 & 0.0266 & 30.9959 & 0.0000 & & & \\
\hline & SCVR & $\rightarrow$ & NORMCOM & 0.1286 & 0.1509 & 0.8522 & 0.3945 & & & \\
\hline
\end{tabular}

Unlike previously, $R^{2}$ values here are quite large. They range from $21.95 \%$ to $86.17 \%$. Using the criteria by Cohen, Cohen, West and Aiken (2003) and Rahman et al (2013), these values are substantial. All $Q^{2}$ values are reasonably large and positive signifying that the models have predictive relevance.

Looking at the path coefficients in model 3, all dimensions of SCV is seen to have a positive effect on OC 
except SCVATO which has a negative impact on OC. Irrespective of this, only SCVMV has a significant impact on OC $(\beta=0.8378, p<0.001)$.

Model 4 shows how the sub components affect affective commitment. Although mostly positive impact, there is no statistical evidence with this sample to reject the hypothesis that SCVC, SCVATO, SCVF and SCVR have a significant impact on affective commitment. SCVMV however has a significantly positive impact on affective commitment $(\beta=0.4817, p<0.001)$. This pattern becomes evident when model 5 and model 6 are also considered. Out of all the dimensions of SCV, only SCVMV is seen to have a significant impact on affective commitment $(\beta=0.4817, p<0.001)$, continuous commitment $(\beta=0.7256, p<0.001)$ and normative commitment $(\beta=0.8233, p<0.001)$. For all of these significant effects, positive impacts were observed.

\section{Discussions}

As expected, the SEM/PLS analysis demonstrated that there was a significant positive effect of socio-cultural values on organizational commitment (affective commitment, Continuance commitment and normative commitment). This indicates that managers greatly adhered to their socio-cultural values (moral values, attitude toward others, religious values, family values and communalism). In fact, evidence has shown that adherence to socio-cultural values improved the Bank Managers organizational commitment which corroborates some previous studies (e.g., Abdul et al., 2013; Gelder, 2012; Mayhew, 2015). What accounted for the positive effect of socio-cultural values as a composite on the managers' organizational commitment was specifically their adherence to moral values mainly though the other values such as religious values, communal values, family values and attitude toward others also had some positive effects on some of the components of commitment. What seemed worthy of note is the value the manager place on moral values.

It is noteworthy that the manager's moral value was more salient in influencing their organizational commitment as found in some previous studies (e.g. Abdul et al., 2013 and Gelder, 2012). This is evident in Gyekye's (2003) book in which he indicated that Ghanaians are brought to have good morals from infancy. Children who exhibit bad moral attitudes are disciplined by their parents or even other elders in the society. These moral values guide individuals' behavior and attitude wherever they may find themselves. Good morals capture doing the right thing at all time. For this reason an employee will show commitment to his or her job because he/she knows that he is being paid to work and therefor have to be committed to his work in order to increase productivity.

The managers, however, did not consider their family values, communal living and attitude toward others as prominent cultural values to have any positive effect on some components of commitment at work. These were also statistically irrelevant in explaining the managers' organizational commitment. This provides ample evidence that the findings are appropriate for theory building.

\section{Conclusion}

The results revealed a strong influence of socio-cultural values on organizational commitment (affective commitment, continuance commitment and organizational commitment). The findings provide support for socio-cultural subsystem model and also supported Nukunya (2013) who indicated that culture influences employees' work ethics and attitudes. Adhering to socio-cultural values by the bank managers had a significant positive effect on their organizational commitment. The findings of this study provide enough evidence for policy prescription at the workplace that will incorporate employees' socio-cultural values with the organizational culture which in effect will increase organizational commitment level of workers.

\subsection{Practical implications}

The findings of the study provide some practical implications for policy makers, employers and employees. It suggests that employers and management should consider integrating employees' socio-cultural values into the 
organizational culture to embrace employees' values and make them feel cherished by the organizations which in effect will increase organizational commitment. Considering only the organizational culture alone may not be appropriate since individuals belong to a society which has its own cultural values and expectations. So to argue that individuals should leave their socio-cultural values behind when they come to work may be difficult, hence may affect their attitudes toward work negatively. Industrial and Organizational Psychologists and Human Resource Managers should now appreciate and understand that in designing work, creating any work environment or work culture, employees' socio cultural values that pertain to the location of the organization must be taken into consideration

\subsection{Practitioner points}

$>\quad$ The findings of the study clearly indicate the need for incorporating the cardinal cultural values into the work culture to satisfy employees hence to have positive attitudes towards work to employees who cherish their cultural values and cannot leave them at home since they are also part and parcel of who they are.

$>\quad$ Practitioners should be flexible enough at the workplace and create a flexible working atmosphere for employees to make them feel more cherished or important at work.

\section{References}

Abbott, G. N., White, F. A., \& Charles, M. A. (2005). Linking values and organizational commitment: A correlational and experimental investigation in two organizations. Journal of Occupational and Organizational Psychology, 78(1), 531-551. https://doi.org/10.1348/096317905X26174

Abdul, A. H. M., Jusoh, M. S., Amlus, M. H., \& Halim, M. S. A. (2013). The mediating role of adaptability cultural trait approach on transformational leadership style and job satisfaction in the work environment: A study on Malaysian GLCs. International Journal of Business and Technopreneurship, 3(3), 423-448.

Akuoko, K. O. (2008). Traditional values, socio-cultural factors and human resource management practices in public sector organizations in Ghana. Journal of Science and Technology, 28(3), 68-69.

Ali, S., Akuahmoah-Boateng, R., Bowa, M., Carr, C.S., Ehiobuche I., Griff, P., ... Zimba, C. (2001). Indigenizing organizational change: Localization in Tanzania and Malawi. Journal of Managerial Psychology, 16(1), 59-78. https://doi.org/10.1108/02683940110366579

Allen, N. J., \& Meyer, J. P. (2000). Construct validation in organizational behavior research: The case of organizational commitment. In Goffin, R. D. \& Helmes, E. (Eds.), Problems and solutions in human assessment: Honoring Douglas N. Jackson at seventy (pp. 285-314). Norwell, MA: Kluwer. https://doi.org/10.1007/978-1-4615-4397-8_13

Apekey, A. K. (2001). Traditional values and management in Ghana (Unpublished PhD. Thesis). Legon: University of Ghana.

Chusmir, L. H., \& Koberg, C. S. (1988). A look at sex differences in the relationships between religious beliefs and work-related attitudes. Journal of Social Behavior \& Personality, 5(2), 34-57.

Cohen, J., Cohen, P., West, S. G., \& Aiken, L. S. (2003). Applied multiple regression/ correlation analysis for the behavioral sciences ( $3^{\text {rd }}$ ed.). New Jersey, London: Lawrence Erlbaum Associates, Publishers, Mahwah.

Ebrahimi, A., \& Nasir, H. (1996). Study of the relationship between religious motivation and the quality of religious practice with geriatric depression and despair in sanatoriums of Isfahan. In the Proceedings of the First National Conference of Geriatric Psychiatry (pp. 63-68). Sari.

Gbadamosi, G. (2003). HRM and the commitment rhetoric: Challenges for Africa. Management Decision, 4(3), 274-280. https://doi.org/10.1108/00251740310475218

Gelder, K. M. (2012). Understanding the role of cultural values in the experience of work-family conflict among professional Latinas (pp. 24-56). Columbia University Academic Common.

Gyekye, S. A. (2003). Causal attributions of Ghanaian industrial workers for accident occurrence: Miners and non-miners perspective. Journal of Safety Research, 34(5), 533-538. 
Opoku Mensah, A.

https://doi.org/10.1016/j.jsr.2003.03.002

Haenlein, M., \& Kaplan, A. M. (2004). A beginner's guide to partial least squares analysis. Understanding Statistics, 3(4), 283-297. https://doi.org/10.1207/s15328031us0304_4

Hair, J. F., Hult, G. T. M., Ringle, C. M., \& Sarstedt, M. (2014). A primer on partial least squares structural equation modeling (PLS-SEM). Sage Publication.

Henseler, J., Ringle, C. M., \& Sinkovics, R. R. (2009). The use of partial least squares path modeling in international marketing. In R. R. Sinkovics \& P. N. Ghauri (Eds.), Challenges to international marketing (Vol. 20, pp. 277-319). Emerald Group Publishing.

Hofstede, G. (1980). Cultures consequences: International differences in work related values. Beverly Hills, CA: Sage.

Lincoln, J. R., \& Kalleberg, A. L. (1985). Work organization and workforce commitment: A study of plants and employees in the US and Japan. American Sociological Review, 1(1), 738-760. https://doi.org/10.2307/2095502

Mathwick, C., Malhotra, N., \& Rigdon, E. (2001). Experiential value: conceptualization, measurement, and application in the catalog and internet shopping environment. Journal of Retailing, 77(1), 39-54. https://doi.org/10.1016/S0022-4359(00)00045-2

Mayhew, R. (2015). Why is respect important in a diverse workplace? Small business by Demand Media. Retrieved from http://smallbusiness.chron.com/respect-important-diverse-workplace-11475.html

Mortimer, J. T., \& Lorence, J. (1995). Social psychology of work. In Sociological perspectives on social psychology (pp. 497-521). Allyn and Bacon.

Mugunthan, S. (2013). A study of work-family conflict and job satisfaction. International Journal of Social Science and Interdisciplinary Research, 2(7), 1-12.

Nukunya, G. K. (2013). Sociology and national development. Paper presented in the Re-Launch of the Ghana Sociological Association, Legon.

Prenkert, F. (2012). Business network simulation: combining research cases and agent-based models in a robust methodology. International Journal of Business Administration, 3(6), 82-91. https://doi.org/10.5430/ijba.v3n6p82

Rahman, I.A., Memon, A.H., \& Karim, A.T.A. (2013). Examining factors affecting budget overrun of construction projects undertaken through management procurement method using PLS-SEM approach. Procedia-Social and Behavioral Sciences, 107(1), 120-128. https://doi.org/10.1016/j.sbspro.2013.12.407

Ringle, C. M., Sarstedt, M., \& Straub, D. (2012). A critical look at the use of PLS-SEM in MIS Quarterly. MIS Quarterly, 36(1), 34-41.

Rogers, J., \& Franzen, A. (2014). Work-family conflict: The effects of religious context on married women's participation in the labor force. Religions, 5(3), 580-592. https://doi.org/10.3390/rel5030580

Ruiz, D. M., Gremler, D. D., Washburn, J. H., \& Carrion, G. C. (2010). Reframing customer value in a service-based paradigm: An evaluation of a formative measure in a multi-industry, cross-cultural context. In V Esposito Vinzi et al., (Eds.), Handbook of partial least squares (pp. 535-566). Berlin: Springer. https://doi.org/10.1007/978-3-540-32827-8_24

Saari, L. M., \& Erez, M. (2002). Cross-cultural diversity and employee attitudes. Paper presented in the 17th Annual Conference of the Society for Industrial and Organizational Psychology, Toronto.

Saari, L. M., \& Judge, T. A. (2004). Employee attitudes and Job Satisfaction. Journal of Human Resource Management, 43(4), 395-407. https://doi.org/10.1002/hrm.20032

Tahmincioglu, E. (2012). Religion at work can bring fire and brimstone. Retrieved from http://www.today.com/money/religion-work-can-bring-fire-brimstone-460844 